\title{
Changes in Chemical Composition of Dissolved Organic Matter in Solar Ponds From Salt Lake Brine
}

\author{
Keli Yang ( $\nabla$ yangkl@isl.ac.cn ) \\ Qinghai Institute of Salt Lakes, Chinese Academy of Sciences \\ Yaoling Zhang \\ Qinghai Institute of Salt Lakes, Chinese Academy of Sciences \\ Yaping Dong \\ Qinghai Institute of Salt Lakes, Chinese Academy of Sciences \\ Jiaoyu Peng \\ Qinghai Institute of Salt Lakes, Chinese Academy of Sciences \\ Wu Li \\ Qinghai Institute of Salt Lakes, Chinese Academy of Sciences
}

\section{Research Article}

Keywords: Dissolved organic matter, Salt lake brine, Solar pond, Mineral extraction, Transformations

Posted Date: July 9th, 2021

DOl: https://doi.org/10.21203/rs.3.rs-590732/v1

License: (1) This work is licensed under a Creative Commons Attribution 4.0 International License. Read Full License 


\section{Abstract}

The abundance and chemical composition of dissolved organic matter (DOM) in the brine of solar ponds influence efficiency of mineral extraction and rates of brine evaporation, and cause undesired odor and color of the products. In this paper, we report an investigation on changes of DOM compositions in solar ponds from salt lake brine through different approaches. The results showed that the DOM was primarily composed of carbohydrates, aliphatic and aromatic compounds. Dissolved organic carbon (DOC) analysis revealed that the concentration of DOC in solar pond increased with exposure time, and up to 15-fold upon evaporation/irradiation of salt lake brine. Analyses with the elemental composition, Fourier transform infrared spectroscopy (FTIR) and cross polarization magic angle spinning (CP/MAS) ${ }^{13} \mathrm{C}$ nuclear magnetic resonance (NMR) indicated that the relative abundance of aliphatic compounds (including functionalized ones) increased in solar pond process, while an opposite phenomenon was observed for carboxylic acid moieties, aromatics and carbohydrates. Pyrolysis-gas chromatography-mass spectrometry (Py-GC-MS) revealed that most of the DOM in salt lake brine contained methylene chain, terpenoid-like, carbohydrate and/or aromatic structures. The presence of some sulfur-containing organics implied some anaerobic biotic decays, but microbiological processes were probably subordinate to photo-induced DOM transformations. In the salt lake brine, exposuredriven decay decreased the abundance of polysaccharides and increased that of mono- and polyaromatic pyrolysis products. Finally, the implications and guidelines for removing DOM from brine in the process of brine resource exploitation were discussed.

\section{Introduction}

A solar pond is a system of trapping and storing solar energy for extensive applications, such as heating of buildings (Shah et al., 1981; Newell et al., 1990), desalination (Hull and Nielsen, 1989), power production (Tabor and Doron, 1990; Sherman and Imberger, 1991), the addition of heat from external sources (Ganguly et al., 2018) and hydrogen production (Karakilcik et al., 2018). Also, several studies have been made in mineral processing with solar pond technology to achieve the temperature requirements of the flotation stage in last decades (Nie et al., 2011; Garrido et al., 2012; Yu et al., 2015; Alcaraz et al., 2018; Montalà et al., 2019).

Brine water usually contains raw materials such as potassium chloride, lithium carbonate, boron, sodium and magnesium for mineral extraction (Zheng, 2011; Bian et al., 2017; Peng et al., 2017). Due to the technically and economically viable, solar pond has been used successfully in mineral extraction from brine water (Nie et al., 2011; Yu et al., 2015). Dissolved organic matter (DOM), the most active fraction in solar pond, often has adverse effects in the process of mineral extraction related to an evaporation rate and a degree of brine evaporation, and further affects quality of products (e.g. smell, color and purity) due to its absorption for most of the sunlight as well as its complexed behaviors with inorganic components (Scully and Lean, 1994; Zhao, 2008, 2010; Shalev et al., 2018). To more efficiently utilize brine resources, it is important to remove their DOM to meet market demands for high value products nowadays such as battery-grade lithium carbonate.

Various physical, chemical and biological technologies have been proposed for DOM removal from brine. Zhao (2010) used a modified ultrafiltration membrane to remove more than $90 \%$ of the total organic carbon (TOC) of salt lake brine, and generated a superior grade of $\mathrm{BaSO}_{4}$. A hydrogen peroxide oxidation method (Zhang et al., 2008) allowed for a removal of colored DOM in salt lake brine from the Yuncheng. This method yielded $60 \%$ removal efficiency and the whiteness of products was obviously enhanced. Nevertheless, treatments targeting a DOM removal often fail to produce a desired result. This is mainly attributed to the presence of an inherently recalcitrant DOM fraction. Research showed that aromatic, humified and higher molecular weight fractions of DOM were more efficiently removed by photochemical degradation than by biological treatments (Xu et al., 2018a), while the reverse was true for carbohydrates (Xu et al., 2016). Moreover, chemical oxidation methods were not suitable for alkane series (Peter and Yoshimoto, 2018), and it was difficult to remove low molecular weight DOM by membrane technology. Thus, knowledge on the chemical structures of brine DOM is required to develop treatment strategies for an efficient removal of DOM.

The Qinghai - Tibet Plateau is the largest plateau in China and the highest plateau in the world, and mainly consists of east west oriented mountain range, wide valleys, and flat highland $>4000 \mathrm{~m}$ altitude (Zheng, 2011). Salt lake brine is widespread this region. The brine is rich in mineral resources (e.g. halite, potash and borate) and some of them reach the cut-off grade of exploitation. Due to lack of mineral energy, construction of solar pond has become a widely used technique in the production of minerals from brine for their capacity to capture and store solar energy, especially in Qinghai - Tibet Plateau region, with excellent 
solar energy resources (Nie et al., 2011; Yu et al., 2015), which provides a partial solution to mineral energy shortages. In addition to lithium, boron, potassium, bromide and other useful trace elements that are of great economic value, DOM are also an important part of brine. The chemical evolution of different types of inorganic constituents has been extensively investigated (Cui et al., 2015; Li et al., 2018; Zhang et al., 2018). However, a lack of knowledge on the composition, distribution and variation of DOM in this system negatively affects further development of mineral extraction strategies.

In this study, the changes of chemical composition of DOM derived from solar ponds were investigated using Da Qaidam Salt Lake brine, located in Qaidam basin, Qinghai - Tibet Plateau region. Solid-phase extraction with PPL cartridges, which reportedly produced high DOC recovery and representative DOM fractions (Yang et al., 2017a; Yang et al., 2017b), was used to isolate DOM from the hypersaline water. The DOM was characterized using elemental composition, Fourier transform infrared spectroscopy (FTIR), ${ }^{13} \mathrm{C}$ nuclear magnetic resonance spectrometry $\left({ }^{13} \mathrm{C}\right.$ NMR) and pyrolysis - GC - MS (Py - GC - MS). This work is an initial step in extending our knowledge on the roles of DOM played in solar ponds, which is also essential to guide development of treatment strategies for these brines.

\section{Materials And Methods}

\subsection{Sites description and sampling}

The brine of salt lake, located in the central of Qaidam basin, Qinghai-Tibet plateau, contains huge amounts of useful mineral elements (e.g. potassium, lithium, boron, sodium and magnesium), which have been well described in our previous studies (Yang et al., 2017a). Due to the shortage of fossil fuel in this remote area, solar pond technology is the main solution to separate and extract minerals from brine. Industrial mineral exploitation in Da Qaidam Salt Lake is mainly conducted by the mining company Dahua Industry Company Ltd., which has built a production plant and has produced potassium chloride, potassium sulfate and lithium chloride since 2003.

The solar ponds were constructed near the salt lake (Da Qaidam Salt Lake, $37^{\circ} 50^{\prime} 50^{\prime \prime N} \varangle 95^{\circ} 14^{\prime} 42^{\prime \prime} \mathrm{E}$ ). The solar pond of Da Qaidam Salt Lake (Fig. 1), used to obtain primary products of potash, includes the initial brine pond (SIP), sodium pond (SSP), regulation pond (SRP), carnallite pond (SCP, the main pond for primary commodity extraction) and bittern pond (SBP). The brine samples of different stage of solar pond were collected in two periods (2017 and 2018). Each sample was filtered immediately with $0.7 \mu \mathrm{m} \mathrm{GF} / \mathrm{F}$ glass fiber (Whatman, pre-combusted at $450{ }^{\circ} \mathrm{C}$ for $5 \mathrm{~h}$ ) in the field. Subsequently, the $<0.7 \mu \mathrm{m}$ samples were covered with ice packs in dark, and transported as soon as possible to lab for DOM isolation and purification.

\subsection{Physical and chemical characterization}

The dissolved fraction of total, inorganic, and organic carbon concentrations of the brine samples were determined using a total organic carbon analyzer (AnalytikJena multi N/C 3100, Germany) with a high-temperature catalytic oxidation method. The contents of major cations and anions such as $\mathrm{Na}^{+} \mathrm{Mgg}^{2+}$ and $\mathrm{Cl}^{-}$were determined by traditional titration methods. The concentration of $\mathrm{Li}^{+}$analyzed performed on inductively coupled plasma optical emission spectroscopy (ICAP 6500 Duo, Thermo Scientific). All the mentioned data were obtained by three analytical replicates.

\subsection{Isolation and purification of DOM}

The DOM samples were isolated and purified following a procedure established in our previous studies (Yang et al., 2017a; Yang et al., 2017b). Briefly, the PPL cartridges (Agilent Technologies, USA) was activated with methanol. Next, aliquots of acidified samples ( $\mathrm{pH}$ 2) were passed through the cartridges using a pump (Gast Company, USA) at a flow rate of $3 \mathrm{~mL} / \mathrm{min}$. Before elution, the cartridges were rinsed with $0.01 \mathrm{~mol} / \mathrm{L} \mathrm{HCl}$ to remove excess salts. The DOM were eluted with methanol, and were dried and stored in a desiccator for further analysis. Blank controls were conducted with Milli-Q water acidified using $\mathrm{HCl}(\mathrm{pH} 2)$ as the same procedure.

\subsection{Elemental analysis}


The contents of $\mathrm{C}, \mathrm{H}$ and $\mathrm{N}$ of the purified DOM samples was investigated in duplicate performed on an elemental analyzer equipment (EL CUBE, Germany). The percentage of oxygen was calculated by subtracting the relative contents of $\mathrm{C}, \mathrm{H}$ and $\mathrm{N}$ from $100 \%$, and trace fractions of $S$ and $P$ were ignored herein. The carbon stable isotopic determination $\left(\delta^{13} \mathrm{C}\right)$ was determined using a Delta plus XP isotope ratio mass spectrometer (Thermo Finnigan, USA), and its equation following as:

$$
\delta^{13} \mathrm{C} \text { value }(\% \mathrm{o})=\left[\left(R_{\text {sample }} / R_{\text {standard }}\right)-1\right] \times 100 \%
$$

in which $R$ is the ratio of ${ }^{13} \mathrm{C} /{ }^{12} \mathrm{C}$.

\subsection{FTIR analysis}

The spectra of FTIR were obtained using a FTIR spectrometer (Thermo Nicolet NEXUS 670, USA) from 400 to $4000 \mathrm{~cm}^{-1}$ with 64 scans. Pellets were prepared by pressing sample and $\mathrm{KBr}$ (spectroscopy grade, 1:100) under vacuum. Prior to analysis, the FTIR spectra and second-derivative spectra were normalized, and the reconstructed data matrix was then progressed using the drawing software.

\subsection{Solid-state ${ }^{13}$ C NMR analysis}

Cross polarization/magic angle spinning solid (CP/MAS) nuclear magnetic resonance $\left({ }^{13} \mathrm{C} N \mathrm{MR}\right)$ spectroscopy were recorded on a Bruker Advance DSX $300 \mathrm{MHz}$, and rotor spin speed at $4500 \mathrm{~Hz}$; the optimum relaxation delay was $3 \mathrm{~s}$, and the contact time was $2 \mathrm{~ms}$.

\subsection{Pyrolysis (Py-GC-MS) analysis}

The pyrolysis of DOM samples were conducted on a pyrolysis instrument (Py, CDS Pyroprobe 2000, USA), which heated by 5 ${ }^{\circ} \mathrm{C} / \mathrm{ms}$ from 250 to $610^{\circ} \mathrm{C}$ and then kept at $610^{\circ} \mathrm{C}$ for 10 s. Pyrolysis products were separated and detected on a GC-MS (QP2010, Shimadzu Corporation, Japan). The split mode was 1:40; helium carrier gas speed was $1 \mathrm{~mL} / \mathrm{min}$; and the capillary column was HP-5MS (length $30 \mathrm{~m} \times$ thickness $0.25 \mathrm{~mm} \times$ diameter $0.25 \mu \mathrm{m}$ ). The MS detector was selected at $70 \mathrm{eV}$ electron ionization, and the $m / z$ scan ranged from 45 to 650 .

\section{Results And Discussion}

\subsection{Physical and chemical characterization}

The $\mathrm{pH}$, total dissolved solid (TDS) and major inorganic content of the five samples were listed in Table 1. The pH was slightly basic in the initial stages of solar pond (7.4 in SIP and 7.2 in SSP) and mildly acidic in the late stages of solar pond samples (6.6 in SRP, 4.6 in SCP, and 4.6 in SBP). The contents of TDS ranged from 273.5 to $479.6 \mathrm{~g} / \mathrm{L}$, which increased 1.7 times resulted from the chemical evolution of brine along the course of natural evaporation] with solar pond technology. The dominated inorganic constituents were $\mathrm{Li}^{+} \square \mathrm{Na}^{+} \square \mathrm{Mg}^{2+} \square \mathrm{K}^{+} \square \mathrm{Cl}^{-} \square \mathrm{B}_{2} \mathrm{O}_{3}$ and $\mathrm{SO}_{4}{ }^{2-}$ in the salt lake brine, however, the varied trends differed. The concentration of $\mathrm{Cl}^{-}$increased from 107.8 to $277.1 \mathrm{~g} / \mathrm{L}, \mathrm{B}_{2} \mathrm{O}_{3}$ increased from 0.6 to $40.1 \mathrm{~g} / \mathrm{L}, \mathrm{Mg}^{2+}$ increased from 15.0 to 114.9 $\mathrm{g} / \mathrm{L}$, and $\mathrm{Li}^{+}$increased from 0.1 to $3.0 \mathrm{~g} / \mathrm{L}$ in the solar pond process. while the reverse results was true for $\mathrm{Na}^{+}$concentration, which decreased from 119.8 to $25.5 \mathrm{~g} / \mathrm{L}$. Moreover, the concentrations of $\mathrm{SO}_{4}{ }^{2-}$ and $\mathrm{K}^{+}$exhibited an initially increase followed by a decline. Differences in trends of inorganic constituent concentrations can be attributed to the different evolution course of inorganic ions along the natural evaporation of brine (Bian et al., 2017). 
Table 1

Variations in physical properties and chemical compositions of the studied salt lake brine samples in the solar pond process.

\begin{tabular}{|c|c|c|c|c|c|c|c|c|c|c|c|c|c|}
\hline Sample & $\mathrm{pH}$ & TDS & DC & DIC & DOC & TN & Major & ns ( $g / \mathrm{L}$ & & & & & \\
\hline & & & & & & & $\mathrm{Cl}^{-}$ & $\mathrm{SO}_{4}{ }^{2-}$ & $\mathrm{B}_{2} \mathrm{O}_{3}$ & $\mathrm{~K}^{+}$ & $\mathrm{Mg}^{2+}$ & $\mathrm{Na}^{+}$ & $\mathrm{Li}^{+}$ \\
\hline SIP & 7.4 & 273.5 & 57.0 & 33.6 & 23.4 & 6.6 & 107.8 & 26.2 & 0.6 & 4.1 & 15.0 & 119.8 & 0.1 \\
\hline SSP & 7.2 & 290.6 & 68.9 & 40.9 & 28.1 & 7.0 & 110.5 & 36.7 & 3.0 & 4.8 & 18.4 & 117.1 & 0.1 \\
\hline SRP & 6.6 & 326.9 & 85.2 & 16.4 & 68.8 & 18.1 & 128.9 & 60.3 & 7.4 & 11.7 & 47.2 & 71.1 & 0.3 \\
\hline SCP & 4.6 & 353.5 & 206.6 & 8.3 & 198.3 & 45.1 & 180.6 & 12.1 & 18.3 & 0.8 & 108.3 & 31.9 & 1.5 \\
\hline SBP & 4.6 & 479.6 & 349.3 & 18.5 & 330.8 & 85.5 & 277.1 & 18.6 & 40.1 & 0.5 & 114.9 & 25.5 & 3.0 \\
\hline
\end{tabular}

The contents of dissolved of total, inorganic, organic carbon and total nitrogen (TN) were listed in Table 1. The dissolved carbon (DC) concentrations exhibited an increasing trend which elevated from 57.0 (SIP) to $349.3 \mathrm{~g} / \mathrm{L}$ (SBP), while dissolved inorganic carbon (DIC) has no systematic trend which ranged from 8.3 (SCP) to $40.9 \mathrm{~g} / \mathrm{L}$ (SSP). The DOC and TDS obviously increased ( $r=$ $0.97, P<0.01)$ with exposure time increasing. This implied that the DOM loss by degradation was compensated by an increased concentration of DOM due to evaporation in the solar pond and/or microbial growth. The DOC and total TN contents were strongly correlated $(r=0.99)$, suggesting that the vast majority of the $\mathrm{N}$ existed in an organic form.

\subsection{Elemental analysis}

The values of elemental compositions, atomic ratios $(\mathrm{H} / \mathrm{C}, \mathrm{O} / \mathrm{C}$ and $\mathrm{N} / \mathrm{C})$, and $\delta^{13} \mathrm{C}$ of the purified DOM samples derived from solar pond in this study were listed in Table 2. The relative contents of $\mathrm{C}, \mathrm{H}, \mathrm{N}$ and $\mathrm{O}$ accounted for $37.1-53.5 \%, 3.8-5.2 \%, 1.9-$ $2.4 \%$ and $39.2-56.2 \%$ of the total mass, respectively. In general, these values were in the same ranges as reported in the literature (Chai et al., 2008; Zhang et al., 2016; Yang et al., 2017a), except that the oxygen content of SRP DOM was slightly high but decline of $\mathrm{H}$ content.

Table 2

Elemental composition, atomic ratios, and stable isotopic analysis of DOM samples.

\begin{tabular}{|lllllllll|}
\hline Sample & \multicolumn{3}{c}{ Mass\% } & \multicolumn{3}{c|}{ Atomic ratio } & \multirow{2}{*}{ S $^{13}$ C\%o } \\
\hline & C\% & H\% & N\% & O\% & H/C & C/N & O/C & \\
\hline SIP & 41.6 & 3.8 & 2.1 & 52.4 & 1.1 & 22.7 & 1.0 & -21.8 \\
\hline SSP & 42.6 & 4.2 & 2.4 & 50.8 & 1.2 & 20.9 & 0.9 & -21.0 \\
SRP & 37.1 & 4.7 & 1.9 & 56.2 & 1.5 & 22.4 & 1.1 & -21.7 \\
SCP & 53.5 & 5.1 & 2.3 & 39.2 & 1.1 & 27.6 & 0.6 & -21.4 \\
SBP & 47.5 & 5.2 & 1.8 & 45.5 & 1.3 & 30.1 & 0.7 & -22.2 \\
\hline
\end{tabular}

To further investigate the structure changes of DOM samples in solar pond process, the atomic ratios of $\mathrm{H} / \mathrm{C}, \mathrm{C} / \mathrm{N}$, and $\mathrm{O} / \mathrm{C}$ were calculated based on the analysis results. The $\mathrm{H} / \mathrm{C}$ ratios is an indicator of the degree of maturity or aromatic condensation of DOM, and that of $\mathrm{C} / \mathrm{N}$ and $\mathrm{O} / \mathrm{C}$ can indicate the contents of $\mathrm{N}$-containing compounds and carbohydrate/carboxylic acid of DOM samples, respectively (Chai et al., 2008). As depicted in Table 2, the DOM samples in initial stages of solar pond generally contained higher values of $\mathrm{H} / \mathrm{C}$ and $\mathrm{C} / \mathrm{N}$ than that of late stages of solar ponds, while $\mathrm{O} / \mathrm{C}$ ratios exhibited an opposite trend. The results indicated that the contents of aliphatics increased but decline of N/O-containing compounds (e.g. carbohydrate/carboxylic acid) with the exposure time increasing in the solar pond process. This can also be confirmed by the results of FTIR and ${ }^{13} \mathrm{C}$ CP/MAS NMR analysis. In addition, The $\delta^{13} \mathrm{C}$ of all DOM samples was relatively constant and ranged from -21.0 to $-22.2 \%$, indicating a significantly in situ origins for this material (Benner et al., 1997; Koprivnjak et al., 2009). 


\subsection{FTIR characterization of DOM}

As depicted in Fig. 2a, the major peaks were located around at $3450 \mathrm{~cm}^{-1}, 3200 \mathrm{~cm}^{-1}, 2920 \mathrm{~cm}^{-1}, 1720 \mathrm{~cm}^{-1}, 1640 \mathrm{~cm}^{-1}, 1410$ $\mathrm{cm}^{-1}$ and $1050 \mathrm{~cm}^{-1}$. The band around $3400 \mathrm{~cm}^{-1}$ is ascribed to the $0-\mathrm{H}$ bonds in water and carbohydrates, and intra- and intermolecular hydrogen bonds in compounds such as phenols, carbohydrates and carboxylic acids (Fan et al., 2013). The peak at $3230 \mathrm{~cm}^{-1}$ could be assigned to the stretching of $\mathrm{N}-\mathrm{H}$ (Wang et al., 2012). The intensities of these peaks were significantly decreased from SIP DOM to SBP DOM, indicating $\mathrm{O}-\mathrm{H} / \mathrm{N}-\mathrm{H}$-containing groups declined in the late stages of solar pond process.

The adsorption peaks at approximately $2970-2920 \mathrm{~cm}^{-1}$ are ascribed to $\mathrm{C}-\mathrm{H}$ stretching of aliphatic $\mathrm{CH}_{3}$ or $\mathrm{CH}_{2}\left(\mathrm{Yang}_{\mathrm{e}}\right.$ et al., 2017a). The peak areas of these DOM samples (except the SSP DOM) for the region $\left(2970-2920 \mathrm{~cm}^{-1}\right)$ increased with exposure time increasing (data not shown), which implied that aliphatic compounds were increasing in the late stage of solar pond process. The trend could be partly attributed to the DOM transformation due to photochemical oxidation of aromatic portions, which leaves the more aliphatics behind (Waiser and Robarts, 2000).

The adsorption bands at $1720 \mathrm{~cm}^{-1}$ and $1410 \mathrm{~cm}^{-1}$ indicated that the protonated/de-protonated carboxylic acid functional group were present (Abdulla et al., 2010b). The peaks around the center of $1640 \mathrm{~cm}^{-1}$ location are assigned to the $\mathrm{C}=0$ stretching in amide I and the vibration of $\mathrm{N}-\mathrm{H}$ or $\mathrm{C}-\mathrm{C}$ stretching of aromatic rings. A weak band in the $1050 \mathrm{~cm}^{-1}$ is attributed to $\mathrm{C}-\mathrm{O}$ stretching of carbohydrates (Li et al., 2017). As depicted in Fig. 2b, these peak intensities were significantly decreasing from SIP DOM to SBP DOM. Moreover, the second derivative spectra suggested that both the band of N-H/C-N vibration in amide II $\left(1540 \mathrm{~cm}^{-1}\right)$ and the band of aromatic ring vibration $\left(1515 \mathrm{~cm}^{-1}\right.$ ) (Abdulla et al., 2010a) also exhibited the decreasing trend. These results indicated that the relative contents of carboxylic acids, aromatics, carbohydrates and nitrogen-containing compounds were decreasing in the solar pond process.

\section{$3.4{ }^{13} \mathrm{C}$ CP/MAS NMR spectroscopy}

In general, the ${ }^{13} \mathrm{C}$ NMR spectra (Fig. 3) can be divided into seven main regions, i.e. 0-45 ppm (alkyl C), 45-65 ppm (methoxyl/Nalkyl C), 65-110 ppm (O-alkyl C), 110-145 ppm (aromatic C), 145 - 160 ppm (aromatic C-0), 160-190 ppm (carboxyl/amide C) and 190-220 ppm (carbonyl C). The corresponding normalized distributions of these regions were estimated using the instrument's software (Table 3).

Table 3

The relative carbon percentage of DOM functional groups and compound classes (total aliphatic and total aromatic) obtained from ${ }^{13} \mathrm{C}$ NMR spectra.

\begin{tabular}{|lllllllllll|}
\hline $\begin{array}{l}\text { Chemical } \\
\text { shift, } \\
\text { ppm }\end{array}$ & $\begin{array}{l}\mathbf{0 -} \\
\mathbf{4 5}\end{array}$ & $\mathbf{4 5 - 6 5}$ & Total & $\begin{array}{l}\mathbf{6 5 -} \\
\mathbf{1 1 0}\end{array}$ & $\begin{array}{l}\mathbf{1 1 0 -} \\
\mathbf{1 4 5}\end{array}$ & $\begin{array}{l}\mathbf{1 4 5 -} \\
\mathbf{1 6 0}\end{array}$ & Total & $\mathbf{1 6 0 - 1 9 0}$ & $\mathbf{1 9 0 - 2 2 0}$ \\
\hline $\begin{array}{l}\text { Structural } \\
\text { category }\end{array}$ & $\begin{array}{l}\text { Alkyl } \\
\text { C }\end{array}$ & $\begin{array}{l}\text { Methoxyl/N- } \\
\text { alkyl C }\end{array}$ & Aliphatic & $\begin{array}{l}\text { O- } \\
\text { alkyl } \\
\text { C }\end{array}$ & $\begin{array}{l}\text { Aromatic } \\
\text { C }\end{array}$ & $\begin{array}{l}\text { Aromatic } \\
\text { C-O }\end{array}$ & Aromatics & $\begin{array}{l}\text { Carboxyl/Amide } \\
\text { C }\end{array}$ & $\begin{array}{l}\text { Ketones, } \\
\text { aldehydes }\end{array}$ \\
\hline SIP & 33.5 & 15.9 & 49.5 & 26.1 & 5.4 & 1.6 & 7.1 & 15.7 & 1.7 \\
\hline SSP & 35.8 & 15.9 & 51.7 & 26.2 & 4.3 & 1.3 & 5.6 & 15.6 & 1.0 \\
\hline SRP & 36.8 & 16.5 & 53.2 & 23.3 & 4.7 & 1.5 & 6.2 & 16.0 & 1.3 \\
\hline SCP & 43.1 & 16.3 & 59.3 & 21.7 & 4.4 & 1.3 & 5.6 & 12.6 & 0.7 \\
\hline SBP & 40.5 & 16.8 & 57.2 & 23.0 & 4.1 & 1.2 & 5.3 & 13.4 & 1.0 \\
\hline
\end{tabular}

For the alkyl $\mathrm{C}$ region, the central peak at $24 \mathrm{ppm}$ and $44 \mathrm{ppm}$ could be attributed to $\mathrm{CH}_{3}$ of branched and short-chain compounds, and the $\mathrm{CH}_{2}$ in long-chain structures, respectively (Zhang et al., 2011; Zhang et al., 2016). The methoxyl/N-alkyl C signal corresponds to ether, alcohol and the other hetero-aliphatic compounds (Aiken et al., 1992). The location at $56 \mathrm{ppm}$ which is attributed to the methoxyl carbons attached on the syringyl or guaiacyl in lignin compound was absent. This confirmed a previous 
study that there was virtually no terrestrial-derived DOM input (vascular plants) in the salt lake (Yang et al., 2017a). The 0-alkyl C region was dominated by carbohydrates, including the well-resolved peak at $85 \mathrm{ppm}$ from carbohydrate ring carbon atoms, while the relatively weak signal at 108 ppm was associated with anomeric carbons (Preston and Newman, 1995). For the $110-145$ ppm region, the location at $132 \mathrm{ppm}$ is related to benzene ring carbons, while the aromatic C-O is usually ascribed to phenolic carbon. In the carboxyl/amide carbon region, the central peak at $176 \mathrm{ppm}$ could be ascribed to amide, carboxyl as well as ester carbons. The 190 to 220 ppm region could be attributed to aldehyde and ketonic carbons.

The spectra of all DOM samples were similar, suggesting that the DOM isolated from different solar ponds contained similar group distributions. Among them, the aliphatic, carbohydrate and aromatic carbons accounted for $49.5-59.3 \%, 21.7-26.2 \%$ and $5.3-7.1 \%$ of total signal, respectively (Table 3 ). In general, the aliphatic $\mathrm{C}$ values and methoxyl/ $\mathrm{N}$-alkyl $\mathrm{C}$ showed an increasing trend in the solar pond during an evaporation/irradiation treatment $(r=0.91 ; P<0.001)$, while the 0 -alkyl $C(r=-0.84, P<0.001)$, total aromatics $(r=-0.79 ; P<0.05)$ and carboxyl/amide $C(r=-0.77 ; P<0.001)$ exhibited an opposite trend. The results are well agreed with the observation of elemental composition and FTIR analysis.

\subsection{Changes in the molecular composition of the DOM based on Py - GC - MS analysis}

\subsubsection{Identification of pyrolysis products and their relative proportions of salt lake DOM}

The DOM samples were prolific of compounds with numerous isomers and side-chain configurations, including alkane/alkene pairs, alkyl-substituted monoaromatic and polyaromatic hydrocarbons (MAHs/PAHs) and alicyclic compounds (Table S2). The products were grouped into 11 subclasses based on chemical structures (Table 4). Remaining compounds, including unidentified ones, were labelled as "other compounds".

Table 4

Pyrolysis product groups and relative proportions (\%) of the DOM samples analyzed.

\begin{tabular}{|llllll|}
\hline Categories & SIP & SSP & SRP & SCP & SBP \\
\hline ALICYCL & 25.81 & 24.99 & 27.39 & 28.08 & 25.62 \\
\hline CARB & 26.88 & 24.87 & 27.59 & 21.60 & 19.92 \\
\hline MAH & 16.79 & 17.52 & 17.61 & 20.05 & 22.54 \\
\hline MCC & 11.57 & 15.69 & 11.21 & 11.51 & 11.22 \\
\hline NCOMP & 1.66 & 1.50 & 1.43 & 1.60 & 1.84 \\
\hline OTHER & 5.52 & 4.89 & 4.96 & 5.57 & 6.20 \\
\hline PAH & 3.68 & 3.85 & 3.65 & 4.94 & 5.95 \\
\hline PHEN & 3.65 & 3.49 & 3.28 & 3.50 & 3.88 \\
\hline SCOMP & 2.19 & 0.76 & 1.18 & 0.70 & 0.66 \\
\hline HALOGENCOMP & 1.65 & 0.68 & 0.47 & 1.26 & 1.13 \\
\hline PENT & 0.32 & 0.77 & 0.48 & 0.40 & 0.32 \\
\hline LIG & 0.30 & 0.40 & 0.36 & 0.43 & 0.32 \\
\hline $\begin{array}{l}\text { Abbreviations: ALICYCL = alicyclic compounds, CARB = carbohydrate, MAH = monocyclic aromatic hydrocarbon, MCC = } \\
\text { methylene chain compound, NCOMP = nitrogen-containing compound, PAH = polycyclic aromatic hydrocarbon, PHEN = } \\
\text { phenols, SCOMP = sulphur-containing compound, PENT = Pentanedioic acid, LIG = products of lignin and lignin-like phenolics. }\end{array}$ \\
\hline
\end{tabular}

On the whole, the most abundant group (24.99-28.08\%) was 1-ring unsaturated alicyclic compounds (ALICYCL) based on cyclopentene and cyclohex(adi)enes groups such as cyclohexadiene, $\mathrm{C}_{1}$-cyclohexene, $\mathrm{C}_{1}$-cyclohexadienes (4 isomers), $\mathrm{C}_{2}$ - 
cyclohexadienes (10 isomers), $\mathrm{C}_{3}$-cyclohexadienes (7 isomers) and $\mathrm{C}_{4}$-cyclohexene (limonene). They represented a cyclic aliphatic component of the DOM. They could be terpenoid-derived, and shared similar features to the DOM from the Great Salt Lake (Leenheer et al., 2004). It is argued that the terpenoid-like DOM was probably degradation products of algal and bacterial precursors (pigments and steroids therein). Poorly-identified terpenoid-like structures were often found in the DOM sample, sometimes they contained abundant carboxylic groups. Such carboxylic groups could be present in the source of the alicyclic compounds, and have been eliminated during analytical pyrolysis (decarboxylation).

The second most abundant group (19.92 - $27.59 \%)$ had a structure that is typical of the pyrolysis products of carbohydrates (CARB), such as acetic acid, hydropropanone, hydroxypropanal, cyclopentenones, furans and furaldehydes. These compounds probably originated from microbial polysaccharides, or other kinds of carbohydrates after significant influences of (photo-) degradation. Pyrans and anhydrosugars such as levoglucosan were not detected, suggesting that vascular plant-derived carbohydrates (holocellulose derivatives) were negligible. This is in agreement with the negligible fluxes of rivers and streams in the xeric environments of the Qaidam Basin (Yang et al., 2017a). The carbohydrate products probably reflected a labile component of algae and bacteria. Several salt lake DOM samples from North America also showed a significant carbohydrate component (Domagalski et al., 1989).

Monocyclic aromatic hydrocarbons (MAHs) included benzene and alkylbenzenes with 1 (toluene) to 5 carbon atoms in alkyl groups. This series included mono-unsaturated MAHs such as styrene, and accounted for $16.79-22.54 \%$. The MAHs have been detected in most of the DOM studies, by Py - GC - MS or GC - MS, from (hyper) saline environments. Benzene, toluene, xylenes and other MAHs were also detected in oilfield-produced brine studies using GC - MS of dichloromethane-soluble DOM, indicating that the MAHs were not secondary pyrolysis products of non-aromatic DOM (Yang et al., 2015).

The (linear) n-alkanes, n-alkenes, isoprenoid alkanes and alkenes with a chain length ranging from $C_{6}$ to $C_{23}$ accounted for 11.21 - 15.69\%. They were grouped as methylene chain compounds (MCC). Other MCC such as fatty acids, methylketones, alkylnitriles or alkylamides were not detected. These patterns were probably related to aliphatic material in microbial sources. Lack of phytadienes excluded a significant source in fresh phytoplankton, but intense photo-oxidation could efficiently eliminate such moieties. The isoprenoid compounds included $\mathrm{C}_{9}$-alkadiene (diemethylheptadiene compound), a $\mathrm{C}_{12}$-isoprenoid alkanone and the other unidentified isoprenoid ketones. These were uncommon pyrolysis products and highlighted the idiosyncratic nature of the DOM in hypersaline water. They might originate either from a specific kind of diatom or bacteria, or represent oxidation products of any isoprenoid MCC precursors.

The detected phenols (PHEN) including phenol, methylphenols, $\mathrm{C}_{2}$-alkylphenols ( 4 isomers) and a $\mathrm{C}_{3}$-alkylphenol accounted for $3.28-3.88 \%$. These compounds could originate from many sources such as microbial ones. A partial confusion with $\mathrm{C}_{9}{ }^{-}$ isoprenoid alkatriene groups ( $\mathrm{m} / \mathrm{z} 107$ and 122) for the dimethylphenols could not be excluded.

The sum of compounds with a halogen atom (HALOGENCOMP) in its structure $(0.47-1.65 \%)$ was detected in our study. The compounds included bromomethane ( $\mathrm{MeBr}$ ) and iodomethane (Mel), but other organohalogens could be among the unidentified products. Polycyclic aromatic hydrocarbons (PAHs) were mostly indenes $\left(\mathrm{C}_{0}-\mathrm{C}_{3}\right.$-alkylindenes) and naphthalenes $\left(\mathrm{C}_{0}-\mathrm{C}_{2}\right)$. The extensive methylation was probably indicative of a terpenoid-like or asphaltene source, even though a contamination from sample treatment could not be excluded.

Compounds with nitrogen (NCOMP) in their structures were scarce $(1.43-1.84 \%)$ and dominated by pyrroles (N-methylpyrrole, 2methylpyrrole and 3-methylpyrrole), with traces of benzonitrile and $\mathrm{C}_{3} / \mathrm{C}_{4}$-alkylanilines. These compounds should probably be ascribed to microbial DOM. The lack of indoles, acetamides, cyanobenzenes and diketopiperazines indicated that the N-rich DOM was strongly affected by decay processes, as intact proteins, chitins or peptidoglycans would generate a more diverse N-product fingerprint upon Py - GC - MS. This decay process could also explain the rather low abundance of organic $\mathrm{N}$ in spite of a prevailing microbial source of the DOM: N-rich biopolymers tended to be relatively labile components. The only sulphur-containing products (SCOMP) were benzothiazole, $\mathrm{S}_{2}$ and/or $\mathrm{SO}_{2}(0.66-2.19 \%)$. Identification of thiophene was tentative and was added to the "other compounds". 
A peak with $\mathrm{m} / \mathrm{z} 81,109$ and 124 at the expected retention time of guaiacol was the only possible sign of lignin (LIG), but a source in an isoprenoid alkadiene or trimethylcyclopentenone could not be excluded. Finally, the other compounds (4.89-6.20\%) included numerous unidentified peaks, peaks from plasticizers (phthalic anhydride), $C_{0}-C_{3}$ alkylbenzofurans and a dioxane.

In summary, there were several classes of compounds with an aromatic character (MAH, PAH, PHEN, benzofurans), others with a cyclic aliphatic character (alicyclic compounds, carbohydrate products) and compounds with an acyclic structure (linear alkanes and alkenes, isoprenoid alkanes and alkenes, and pentanoic acid derivatives). Remaining compounds contained atoms such halogen, sulphur or nitrogen.

\subsubsection{Comparison of pyrolysis products of DOM with different origins}

In our previous studies, the DOM samples isolated from solar ponds of oilfield-produced brine (OSDOM) had been investigated by Py - GC - MS analysis (Table S1, S2). Both types of DOM samples produced complex Py - GC - MS fingerprints and it seems clear that they facilitate information on the differences in DOM from the salt lake (SSDOM) and the oilfield-produced brine, and also reflect the effect of prolonged sunlight exposure.

Both sample sets contained many products with linear and isoprenoid polymethylene structures (MCC, i.e. acyclic aliphatic), indicating that: 1) the DOM composition was significantly affected by degradation (MCC are relatively recalcitrant), and 2) a significant portion of the DOM originated from aquatic organisms was prolific of isoprenoids (bacteria and diatoms). This was in agreement with the almost complete absence of alkanes and alkenes with chain lengths over $\mathrm{C}_{23}$, and previous observations that alkanes and alkenes occurred with chain lengths up to $\mathrm{C}_{18}$ (Yang et al., 2017a; Yang et al., 2017b). This implies that vascular plant-derived aliphatic DOM was scarce. The MCC were slightly more abundant in the OSDOM samples and they increased slightly during sunlight exposure. Their abundance might be associated with photo-oxidation of more labile organic constituents.

By contrast, the other main 0-lacking aliphatic components (alicyclic products) were more abundant in the pyrolyzates of the salt lake brine, and decreased in abundance in the oilfield-produced brine due to sunshine exposure. The presence in both sample sets suggest that their precursor was of microbial source (algae and bacteria), possibly relating to terpenoid-like bacterial structures. This was consistent with the results of NMR. These structures would be preferentially degraded in the solar ponds containing the oilfield-produced brine, as they were photochemically and/or biologically labile (Leenheer et al., 2004). Leenheer et al. (2004) performed a radiocarbon dating, showing that virtually all DOM in the Great Salt Lake, similar salt and DOM concentration as the Da Qaidam Salt Lake, was of modern age (kerogen could be a source of the defunctionalized terpenoid structures, but this was not the case). We believe the DOM studied here was also of recent, but nevertheless strongly degraded source.

The same phenomenon was observed for the polysaccharides: they were slightly more abundant in the salt lake brine and were preferentially degraded in the solar pond process. The difference with the alicyclic aliphatic compounds was that, for the carbohydrate products, a decrease due to exposure was more pronounced in the salt lake brine. Hence, the degradation occurring in the salt lake brine eliminated polysaccharides, whereas in the oilfield-produced brine the terpenoid-like component of the DOM was more severely affected. The results were in agreement with those of NMR and FTIR analyses.

Oxygen lacking aromatic DOM products (MAHs and PAHs) were more abundant in the salt lake brine than in the oilfield-produced brine, and the opposite was observed for the O-containing aromatic compounds (in particular, phenols). Their abundance did not change significantly with sunshine exposure time, suggesting that these compounds reflected DOM types of intermediate degradability. Nevertheless, they appeared to correspond to DOM of relatively recalcitrant nature in the salt lake brines (increased in final exposure phases). If the oilfield-produced brine contained significant amounts of petroleum-derived DOM, we would expect higher PAH levels than in the salt lake brine. Hence, it seems that the oilfield-produced brine DOM did not contain oil-derived DOM. Again, a source in microbial terpenoid-like structures was one of the more plausible explanations of the presence of the poly-alkyl substituted PAHs.

The value of the MAHs and PAHs as indications of aromatic DOM in the brine samples was compromised by their possible release from the exchange resins (Daignault et al., 1988). On the other hand, they have often been identified in DOM from (hyper) saline lakes, and are ubiquitous products of pyrogenic and geological OM (kerogen) as well (Witter and Jones, 1999). Many kinds 
of sufficiently degraded sources of organic sources, including humic acids, could produce aromatic groups lacking oxygen after pyrolysis (Song and Peng, 2010).

Chitins (e.g. from brine shrimps) and peptidoglycans (bacterial cell walls) were not recognized. If the DOM were indeed largely bacterial/planktonic, the relatively low nitrogen content (or low abundance of $\mathrm{N}$-containing pyrolysis products), in comparison with fresh aquatic microbial $\mathrm{OM}(\mathrm{C} / \mathrm{N}<10)$, could be explained by preferential decay of proteinaceous groups.

The organohalogen Mel (methyliodide) was much more abundant in the OSDOM than SSDOM and vice versa for MeBr. It also seemed to confirm the high halogen content in the oilfield-produced brine (Zhang, 1987; Tan H et al., 2007).

\subsection{Implications}

This study showed the change of the DOM in the solar ponds, which could be used to evaluate their influences on the cycling of local carbon and nitrogen. Furthermore, the characters of autochthonous-DOM sources in salt lake brine, may give rise to a high potential risk in complexing with organic or heavy metal ion pollutants (Xu et al., 2018b), especially in the salt lake with a high concentration as found in salt lake in Tibet region. This study contributed to a suitable management of brine resources and in particular showed important aspects of the DOM composition and their changes during application of solar pond technology. Identification of DOM in salt lake brine was the first step to develop methods of a separation or removal of brine DOM.

It appeared that the DOC concentration increased during sunlight exposure and that the DOM composition of both brine sources also changed in the solar ponds, probably due to a combination of photodegradation and biodegradation. From the results of the present study, a guideline could be proposed for a removal of the DOM in solar ponds. For instance, the relative content of aliphatic compounds increased whereas aromatics and carbohydrates decreased with a long time sunlight exposure in solar ponds. It is well known that aliphatics are difficult to remove by chemical oxidants such as $\mathrm{O}_{3}$ or $\mathrm{Cl}_{2}$ because of the strength of $\mathrm{C}$ $\mathrm{C}$ bonds, whereas the cleavage of $\mathrm{C}=\mathrm{O}$ or $\mathrm{C}=\mathrm{C}$ are relatively easy ( $\mathrm{Li}$ et al., 2013; Peter and Yoshimoto, 2018). Thus, it is suitable to remove the DOM by oxidants at early stage of solar pond to remove or degrade aromatics and carbohydrates.

\section{Conclusions}

In this paper, the abundance, composition and variations in the DOM quality in solar ponds containing salt lake brine in Qaidam basin (Qinghai - Tibet Plateau) were investigated. The brine DOM samples were primarily composed of aliphatic groups, carbohydrates and aromatic groups, whereas the changes of DOM composition were varied during solar pond exposure treatment. Along with sunshine exposure time increasing, the DOC increased sharply in solar pond. Analyses with elemental composition, FTIR and ${ }^{13} \mathrm{C} C P / M A S ~ N M R$ techniques provided reliable overall variations in the composition of the DOM, in particular that the relative abundance of aliphatics significantly increased with exposure time increasing, whereas the reverse trends were observed for carboxylic acids, aromatics and carbohydrates. The results of Py - GC - MS revealed most of the DOM samples were aliphatic (methylene chain, terpenoid-like and carbohydrate) and aromatic structures, possibly prevalently from bacterial organisms but anyway subject to considerable decays. The presence of some sulfur-containing organics could indicate an anaerobic decay environment, but in the current system microbiological processes were probably subordinate to photo-induced DOM transformation. This study showed significant variations in abundance and DOM structures in solar ponds containing salt lake brine for the first time. In addition, it should be noted that DOM derived from different origins exhibited different changes, which further enhanced our understanding of the behavior and role of the DOM in comprehensive utilization and development of brine resources.

\section{Declarations}

\section{Acknowledgments}

We gratefully thank the Natural Science Foundation of Qinghai Province (2020-ZJ-940Q; 2014-ZJ-937Q), the West Light Foundation of the Chinese Academy of Sciences (E010GC09), and the Youth Innovation Promotion Association CAS (E010GC15) for their financial support. We also sincerely thank to Kaal Joeri for his assistance on identification of pyrolysis products of DOM in this study.

Page $10 / 15$ 


\section{References}

1. Abdulla HAN, Minor EC, Hatcher PG (2010) Using Two-Dimensional Correlations of ${ }^{13} \mathrm{C}$ NMR and FTIR To Investigate Changes in the Chemical Composition of Dissolved Organic Matter along an Estuarine Transect. Environ Sci Technol 44:8044-8049.

2. Aiken GR, McKnight DM, Thorn K, Thurman E (1992) Isolation of hydrophilic organic acids from water using nonionic macroporous resins. Org Geochem 18:567-573.

3. Alcaraz A, Montalà M, Cortina JL, Akbarzadeh A, Aladjem C, Farran A, Valderrama C (2018) Design, construction, and operation of the first industrial salinity-gradient solar pond in Europe: An efficiency analysis perspective. Solar Energy 164:316-326.

4. Benner R, Biddanda B, Black B, McCarthy M (1997) Abundance, size distribution, and stable carbon and nitrogen isotopic compositions of marine organic matter isolated by tangential-flow ultrafiltration. Mar Chem 57:243-263.

5. Bian S, Li D, Gao D, Peng J, Dong Y, Li W (2017) Hydrometallurgical processing of lithium, potassium, and boron for the comprehensive utilization of Da Qaidam lake brine via natural evaporation and freezing. Hydrometallurgy 173:80-83.

6. Chai X, Takayuki S, Guo Q, Zhao Y (2008) Characterization of humic and fulvic acids extracted from landfill by elemental composition, ${ }^{13} \mathrm{C}$ CP/MAS NMR and TMAH-Py-GC/MS. Waste Management 28:896-903.

7. Cui R, Sang S, Li D, Liu Q (2015) Measurements and calculations of solid-liquid equilibria in the quaternary system $\mathrm{NaBr}-\mathrm{KBr}$ $\mathrm{CaBr}_{2}-\mathrm{H}_{2} \mathrm{O}$ at 298 K. Calphad 49:120-126.

8. Daignault SA, Noot DK, Williams DT, Huck PM (1988) A review of the use of XAD resins to concentrate organic compounds in water. Water Res 22:803-813.

9. Domagalski JL, Orem WH, Eugster HP (1989) Organic geochemistry and brine composition in Great Salt, Mono, and Walker Lakes. Geochim Cosmochim Acta 53:2857-2872.

10. Fan X, Song J, Peng P (2013) Comparative study for separation of atmospheric humic-like substance (HULIS) by ENVI-18, HLB, XAD-8 and DEAE sorbents: elemental composition, FT-IR, ${ }^{1} \mathrm{H}$ NMR and off-line thermochemolysis with tetramethylammonium hydroxide (TMAH). Chemosphere 93:1710-1719.

11. Ganguly S, Date A, Akbarzadeh A (2018) Effectiveness of Bottom Insulation of a Salinity Gradient Solar Pond. Journal of Solar Energy Engineering-Transactions of the Asme 140:044502.

12. Garrido F, Soto R, Vergara J, Walczak M, Kanehl P, Nel R, García J (2012) Solar pond technology for large-scale heat processing in a Chilean mine. Journal of Renewable and Sustainable Energy 4:053115.

13. Hull JR, Nielsen CE (1989) Steady-state analysis of the rising solar pond. Solar Energy 42:365-377.

14. Karakilcik M, Erden M, Cilogullari M, Dincer I (2018) Investigation of hydrogen production performance of a reactor assisted by a solar pond via photoelectrochemical process. Int J Hydrogen Energy 43:10549-10554.

15. Koprivnjak JF, Pfromm PH, Ingall E, Vetter TA, Schmitt-Kopplin P, Hertkorn N, Frommberger M, Knicker H, Perdue EM (2009) Chemical and spectroscopic characterization of marine dissolved organic matter isolated using coupled reverse osmosiselectrodialysis. Geochim Cosmochim Acta 73:4215-4231.

16. Leenheer JA, Noyes TI, Rostad CE, Davisson ML (2004) Characterization and origin of polar dissolved organic matter from the Great Salt Lake. Biogeochemistry 69:125-141.

17. Li D, Zeng D, Yin X, Gao D (2018) Phase diagrams and thermochemical modeling of salt lake brine systems. III. $\mathrm{Li}_{2} \mathrm{SO}_{4}+\mathrm{H}_{2} \mathrm{O}$, $\mathrm{Na}_{2} \mathrm{SO}_{4}+\mathrm{H}_{2} \mathrm{O}, \mathrm{K}_{2} \mathrm{SO}_{4}+\mathrm{H}_{2} \mathrm{O}, \mathrm{MgSO}_{4}+\mathrm{H}_{2} \mathrm{O}$ and $\mathrm{CaSO}_{4}+\mathrm{H}_{2} \mathrm{O}$ systems. Calphad 60:163-176.

18. Li DY, Shang XS, Chen GR, Liu PN (2013) Chemlnform Abstract: Solvent-Switched Benzylic Methylene Functionalization: Addition, Ring-Opening, Cyclization, and Unexpected Cleavage of C-O and C-C Bonds. Cheminform 15:3848-3851.

19. Li Y, Harir M, Uhl J, Kanawati B, Lucio M, Smirnov KS, Koch BP, Schmitt-Kopplin P, Hertkorn N (2017) How representative are dissolved organic matter (DOM) extracts? A comprehensive study of sorbent selectivity for DOM isolation. Water Res 116:316-323.

20. Montalà M, Cortina JL, Akbarzadeh A, Valderrama C (2019) Stability analysis of an industrial salinity gradient solar pond. Solar Energy 180:216-225.

Page $11 / 15$ 
21. Newell TA, Cowie RG, Upper JM, Smith MK, Cler GL (1990) Construction and operation activities at the university-of-illinois salt gradient solar pond. Solar Energy 45:231-239.

22. Nie Z, Bu L, Zheng M, Huang W (2011) Experimental study of natural brine solar ponds in Tibet. Solar Energy 85:1537-1542.

23. Peng J, Bian S, Zhang B, Dong Y, Li W (2017) Research on boron recovery from sulfate-type saline lakes with a novel dilution method. Hydrometallurgy 174:47-55.

24. Peter GF, Yoshimoto FK (2018) Formation and Cleavage of C-C Bonds by Enzymatic Oxidation-Reduction Reactions. Chem Rev 118:6573-6655.

25. Preston $C$, Newman $R$ (1995) A long-term effect of $N$ fertilization on the ${ }^{13} \mathrm{C} C P M A S$ NMR of de-ashed soil humin in a secondgrowth Douglas-fir stand of coastal British Columbia. Geoderma 68:229-241.

26. Scully N, Lean D (1994) The Attenuation of Ultraviolet Radiation in Temperate Lakes. Arch Hydrobiol Ergeb Limnol 43:135144.

27. Shah SA, Short TH, Fynn RP (1981) Modeling and testing a salt gradient solar pond in northeast ohio. Solar Energy 27:393401.

28. Shalev N, Lazar B, Köbberich M, Halicz L, Gavrieli I (2018) The chemical evolution of brine and Mg-K-salts along the course of extreme evaporation of seawater-an experimental study. Geochim Cosmochim Acta 241:164-179.

29. Sherman BS, Imberger J (1991) Control of a solar pond. Solar Energy 46:71-81.

30. Song J, Peng Pa (2010) Characterisation of black carbon materials by pyrolysis-gas chromatography-mass spectrometry. J Anal Appl Pyrolysis 87:129-137.

31. Tabor HZ, Doron B (1990) The beith-haarava $5 \mathrm{mw}(\mathrm{e})$ solar pond power-plant (sppp) - progress report. Solar Energy 45:247253.

32. Tan H, Cao C, Li T, Fan Q (2007) Hydrochemistry characteristics and chemical evolution of oilfield brines of the Paleogene and Neogene in western Qaidam Basin. Journal of palaeogeography 9:313-320. (In Chinese with English Abstract)

33. Waiser MJ, Robarts RD (2000) Changes in composition and reactivity of allochthonous DOM in a prairie saline lake. Limnol Oceanogr 45:763-774.

34. Wang X, Goual L, Colberg PJ (2012) Characterization and treatment of dissolved organic matter from oilfield produced waters. J Hazard Mater 217-218:164-170.

35. Witter AE, Jones AD (1999) Chemical characterization of organic constituents from sulfide-rich produced water using gas chromatography/mass spectrometry. Environ Toxicol Chem 18:1920-1926.

36. Xu H, Guan DX, Zou L, Lin H, Guo L (2018a) Contrasting effects of photochemical and microbial degradation on Cu(II) binding with fluorescent DOM from different origins. Environ Pollut 239:205-214.

37. Xu H, Guo L, Jiang H (2016) Depth-dependent variations of sedimentary dissolved organic matter composition in a eutrophic lake: Implications for lake restoration. Chemosphere 145:551-559.

38. Xu H, Yan M, Li W, Jiang H, Guo L (2018b) Dissolved organic matter binding with $\mathrm{Pb}(\mathrm{II})$ as characterized by differential spectra and 2D UV-FTIR heterospectral correlation analysis. Water Res 144:435-443.

39. Yang K, Zhang Y, Dong Y, Li W (2017a) Selectivity of solid phase extraction for dissolved organic matter in the hypersaline Da Qaidam Lake, China. Environmental Science-Processes \& Impacts 19:1374-1386.

40. Yang K, Zhang Y, Dong Y, Nie Z, Li W (2017b) Comparative study of solid-phase extraction of dissolved organic matter from oilfield-produced brine by different sorbents. Environmental Engineering Science 34:675-686.

41. Yang K, Zhang Y, Yuan W, Qian G, Dong Y, Nie Z (2015) Analysis of dissolved organic matter in oilfield produced waters in the Nanyishan Area of the Qaidam Basin. Petrochemical Technology 44:1396-1402. (In Chinese with English Abstract)

42. Yu J, Zheng M, Wu Q, Nie Z, Bu L (2015) Extracting lithium from Tibetan Dangxiong Tso Salt Lake of carbonate type by using geothermal salinity-gradient solar pond. Solar Energy 115:133-144.

43. Zhang P (1987) Saline Lakes of Qaidam Basin. Publishing House of Science, Beijing

44. Zhang T, Zhang W, Cui R, Gao Y, Sang S (2018) Stable and metastable phase equilibria in the ternary system $\mathrm{MgB}_{4} \mathrm{O}_{7}-\mathrm{MgSO}_{4^{-}}$ $\mathrm{H}_{2} \mathrm{O}$ at $273 \mathrm{~K}$. Chiang Mai Journal of Science 45:1921-1932.

Page 12/15 
45. Zhang Y, Du J, Ding X, Zhang F (2016) Comparison study of sedimentary humic substances isolated from contrasting coastal marine environments by chemical and spectroscopic analysis. Environmental Earth Sciences 75:378-391.

46. Zhang Y, Du J, Zhang F, Yu Y, Zhang J (2011) Chemical characterization of humic substances isolated from mangrove swamp sediments: The Qinglan area of Hainan Island, China. Estuar Coast Shelf Sci 93:220-227.

47. Zhao X (2008) Impact of organics in bittern on the quality of $\mathrm{BaSO}_{4}$ products. Inorganic Chemicals Industry 40:34-36. (In Chinese with English Abstract)

48. Zheng M (2011) Resources and eco-environmental protection of salt lakes in China. Environmental Earth Sciences 64:15371546.

49. Zixing Z (2008) Study On the purifieation and deeoloration of salt lake brine. Shanxi University

\section{Figures}

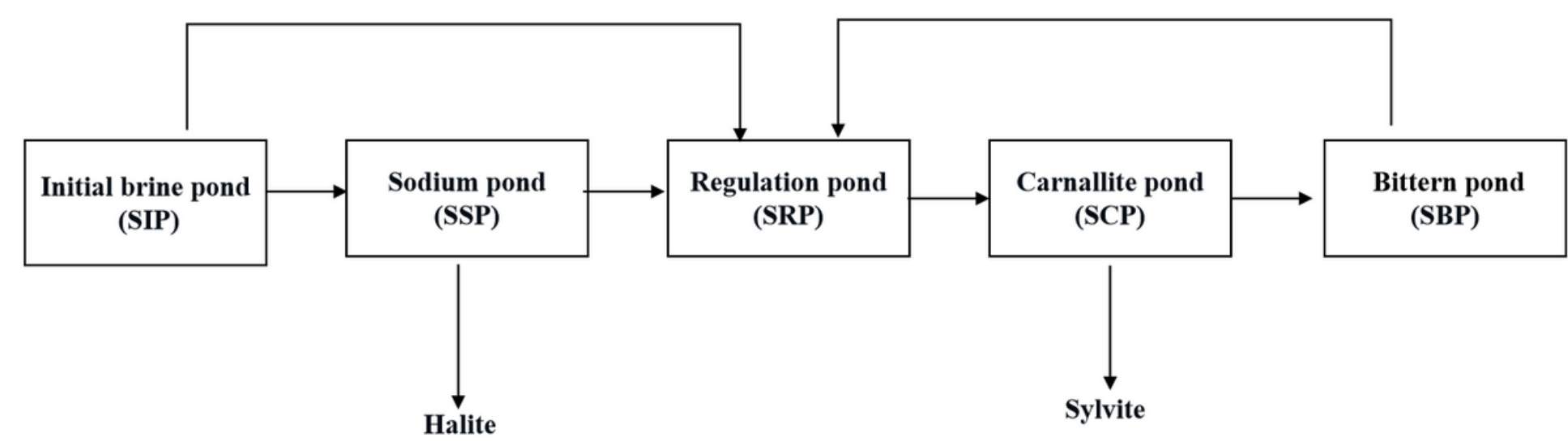

Figure 1

Scheme for the solar pond from salt lake brine. 

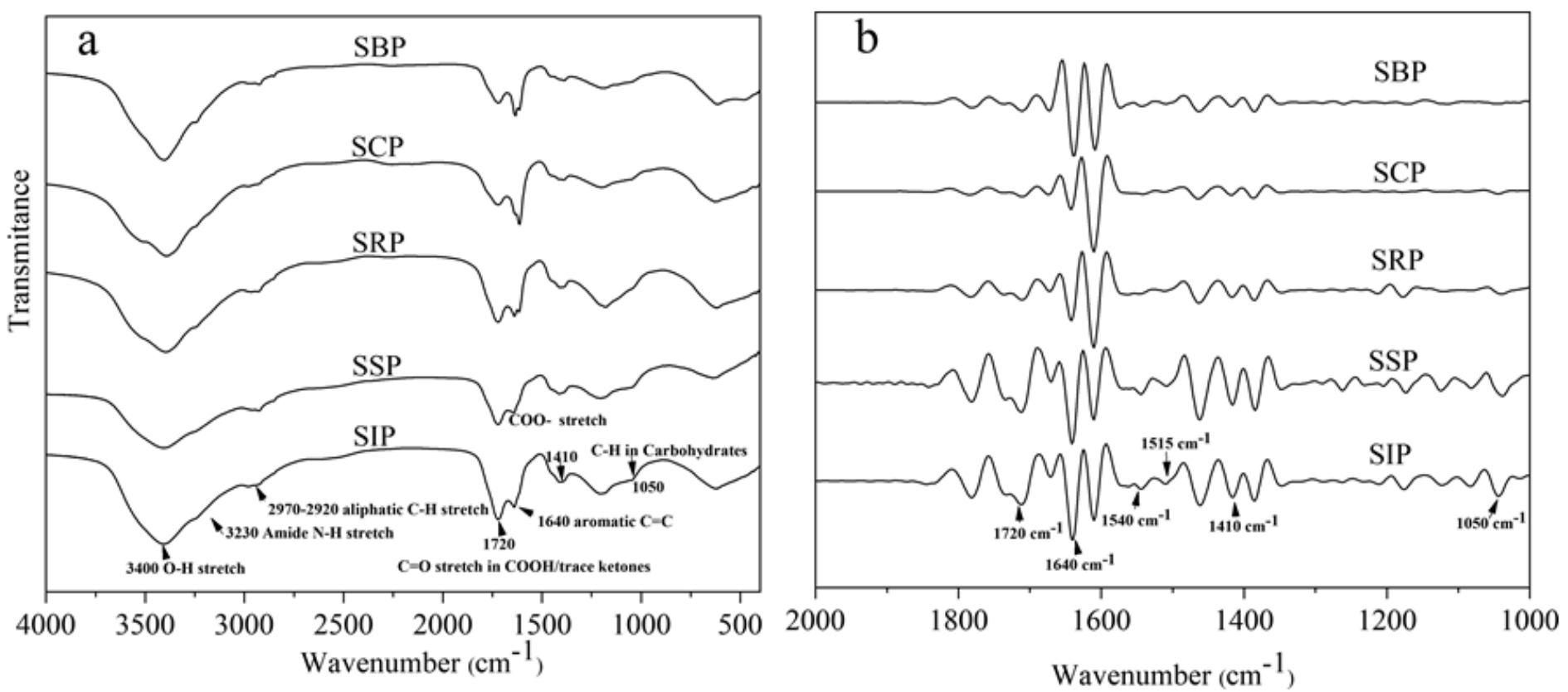

Figure 2

The FTIR spectra of DOM samples isolated from solar pond process (a), and their corresponding second derivative spectra (b).

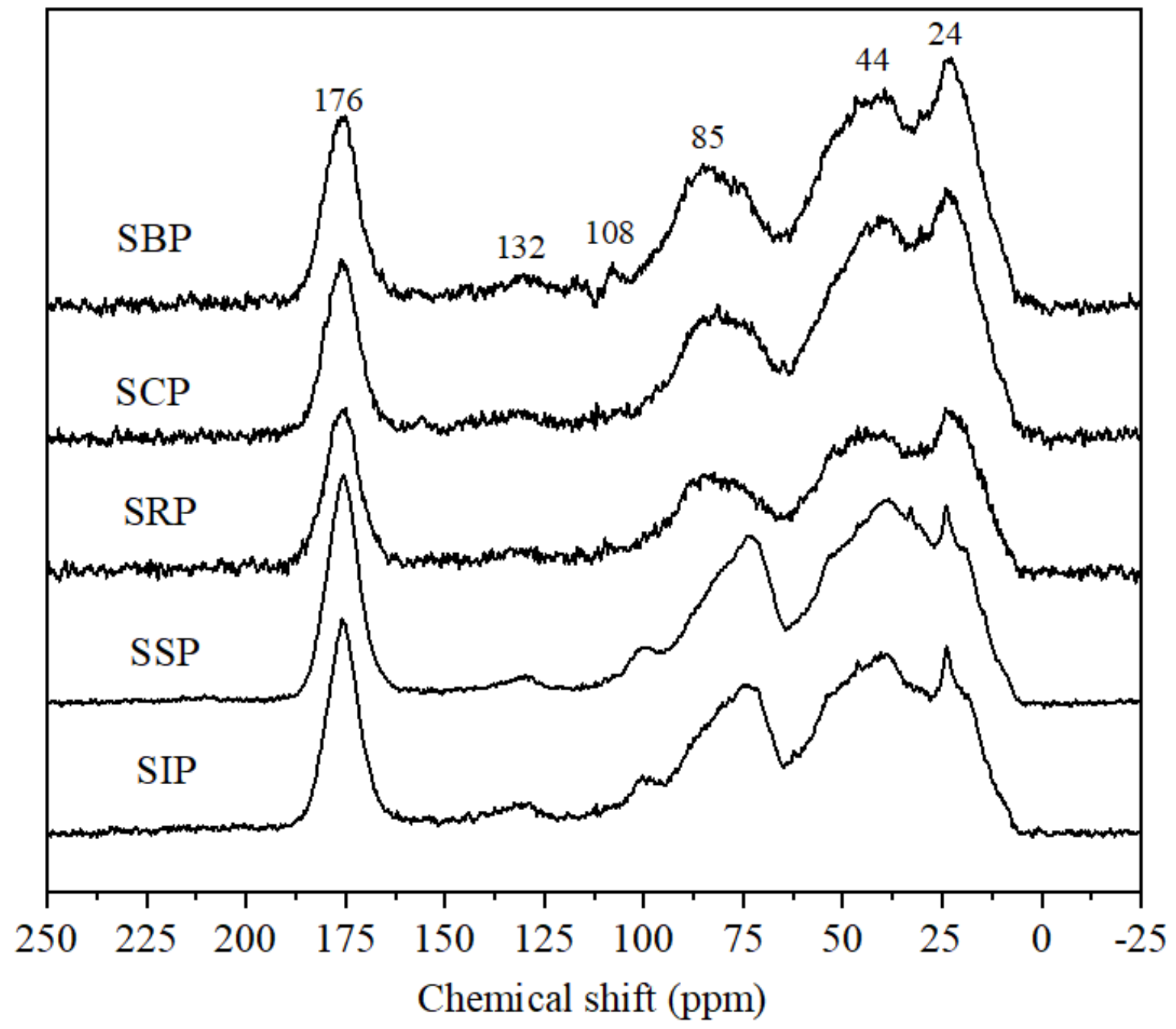


Figure 3

13C NMR spectra of DOM samples.

\section{Supplementary Files}

This is a list of supplementary files associated with this preprint. Click to download.

- SupplementaryMaterial.doc 